\title{
Biphasic Insulin Aspart 30 (BIAsp 30) is Safe and Improves Glycaemic Control in Insulin Naïve Patients with Type 2 Diabetes
}

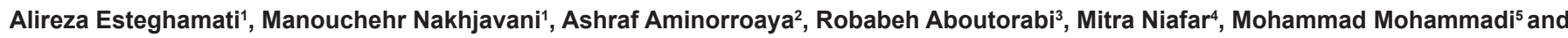
Ehsan Parvaresh ${ }^{6 *}$

${ }^{1}$ Tehran University of Medical Sciences, Tehran, Iran

${ }^{2}$ Isfahan University of Medical Sciences, Tehran, Iran

${ }^{3}$ Mashad University of Medical Sciences, Tehran, Iran

${ }^{4}$ Tabriz University of Medical Sciences, Tehran, Iran

${ }^{5}$ Yazd University of Medical Sciences, Tehran, Iran

${ }^{6}$ Novo Nordisk Pars, Medical \& Clinical Research, Tehran, Iran

\section{Introduction}

Type 2 diabetes mellitus (T2DM) is a progressive disease characterized by gradual decline in beta-cell function and insulin resistance [1]. The recommendations for initial treatment of T2DM include lifestyle adjustments and oral anti-diabetic medications [2]. The United Kingdom Prospective Diabetes Study (UKPDS) and other studies have shown that intensive glycaemic control in type 2 diabetes significantly reduces the risk of development and/or deterioration of microvascular complications [1,3]. The incidence and progression of microvascular complications correlate with the glycaemic control and lower glycated haemoglobin $\left(\mathrm{HbA}_{1 \mathrm{c}}\right)$ levels are associated with the reduction of cardiovascular risks [3]. Both fasting blood glucose (FBG) and post-prandial blood glucose (PPBG) contributes to the level of $\mathrm{HbAlc}$, and current data suggest that postprandial hyperglycaemia is associated with an increased risk of macrovascular disease [4]. Therefore, it seems reasonable to target postprandial hyperglycaemia in addition to FBG levels to achieve maximum benefits $[5,6]$.

Biphasic insulin aspart 30 (BIAsp 30) (NovoMix 30 ) is an insulin analogue mixture which contains $30 \%$ unbound rapid-acting insulin aspart and $70 \%$ intermediate-acting protaminated insulin aspart. This premix formulation aims at postprandial hyperglycaemia and also provides basal insulin coverage [7]. In patients with type 2 diabetes inadequately controlled with OADs, insulin therapy is frequently started by adding basal to existing OADs [8]. BIAsp 30 provides both postprandial plasma glucose and fasting plasma glucose control [9]. In a treat-to-target trial, $41 \%$ of subjects with type 2 diabetes achieved the target of $\mathrm{HbAlc}<7 \%$ on once-daily treatment with BIAsp 30 [10]. In addition, more patients could safely achieve the goals for optimal glycaemic control when the number of daily injections of BIAsp30 increased from one to two, and then if not meeting the $\mathrm{HbA}_{1 c}$ target, from two to three daily injections $[11,12]$.

In Iran, quality of care of patients with type 2 diabetes is poor. It has been reported that only $6.4 \%$ of Iranian patients had $\mathrm{HbA}_{1}$ measurements at least once in a year and majority of them had poor glycaemic control according to their most recent $\mathrm{HbA}_{1 c}$ levels [13].

The aim of the IMPROVE ${ }^{\text {rix }}$ study was to evaluate the clinical safety profile and efficacy while using BIAsp 30 (NovoMix 30 ) under normal clinical practice conditions. Data from a subgroup of insulin naïve patients with type 2 diabetes in Iran are reported. Beneficial information on safety, efficacy and pattern of use of a drug in an extensive patient population can be gained from this observational study.

\section{Patients and Methods}

\section{Study design}

IMPROVE ${ }^{\mathrm{TM}}$ was a 26-week, open-label, non-randomized, multicentre observational study of patients with type 2 diabetes conducted in 11 countries (Canada, China, Greece, Persian Gulf region countries, India, Iran, Italy, Japan, Poland, Russia and South Korea) [14,15]. BIAsp $30(100 \mathrm{IU} / \mathrm{ml})$ was prescribed by the physician in routine clinical evaluations. The starting dose and frequency of injection, as well as subsequent dose adjustments were individualised and were at the discretion of the physician. No study-specific investigations were performed except the collection of data at baseline, follow-up visit (approximately 13 weeks after enrolment), and final visit (approximately 26 weeks after enrolment). Study procedures complied with local regulations and practice governing observational studies. Health authority approval and ethics committee approval were achieved. This is a subgroup analysis from the IMPROVE study. Results from the insulin naïve Iranian patients with T2DM are reported in this paper.

\section{Patients}

Written informed consent was obtained for all patients before any trial-related activity. The study was performed in accordance with the Declaration of Helsinki [16] and International Conference on Harmonisation Good Clinical Practice [17]. Patients recruited in the IMPROVE study were 18 years and older treated with BIAsp 30 in routine clinical practice. Patients were excluded if they had known or suspected allergy to BIAsp 30. Females who were pregnant, breast-feeding or intending to become pregnant were also excluded. This subgroup included insulin naive patients with T2DM who were previously treated with oral anti-diabetic medications only in Iran. The majority of these patients (69.2\%) were on a combination of Biguanides and Sulphonylureas, while $8.8 \%, 9.4 \%$ of patients were on Biguanides only and Sulphonylureas only, respectively. The dose of insulin was not specifically adjusted for OADs but at the physician's discretion.

\section{Endpoints}

The primary endpoint was the incidence of major hypoglycaemic episodes reported as serious adverse drug reactions (SADRs). Major hypoglycaemic episode was defined as an episode with severe central

${ }^{*}$ Corresponding author: Ehsan Parvaresh, Medical Manager, Novo Nordisk Pars, Medical \& Clinical Research, $11^{\text {th }}$ floor, Kian Tower, No. 2551, Vali-e-As Ave., Tehran, Iran (Islamic Republic of), Fax: +982188645230; E-mail: ehpa@ novonordisk.com

Received December 13, 2010; Accepted April 06, 2011; Published April 12, 2011

Citation: Esteghamati A, Nakhjavani M, Aminorroaya A, Aboutorabi R, M Niafar, et al. (2011) Biphasic Insulin Aspart 30 (BIAsp 30) is Safe and Improves Glycaemic Control in Insulin Naïve Patients with Type 2 Diabetes. J Diabetes Metab 2:123. doi:10.4172/2155-6156.1000123

Copyright: @ 2011 Esteghamati A, et al. This is an open-access article distributed under the terms of the Creative Commons Attribution License, which permits unrestricted use, distribution, and reproduction in any medium, provided the original author and source are credited. 
Citation: Esteghamati A, Nakhjavani M, Aminorroaya A, Aboutorabi R, M Niafar, et al. (2011) Biphasic Insulin Aspart 30 (BIAsp 30 ) is Safe and Improves Glycaemic Control in Insulin Naïve Patients with Type 2 Diabetes. J Diabetes Metab 2:123. doi:10.4172/2155-6156.1000123

Page 2 of 5

nervous system symptoms consistent with hypoglycaemia in which the patient was unable to treat himself/herself and had one of blood glucose $<50 \mathrm{mg} / \mathrm{dl}(2.8 \mathrm{mmol} / \mathrm{l})$ or reversal of symptoms after either food intake or glucagon or intravenous glucose administration.

The secondary endpoints included the number of minor hypoglycaemic episodes, changes in body weight and body mass index (BMI), $\mathrm{HbA}_{1 \mathrm{c}}, \mathrm{FBG}$, the variability in FBG, PPBG after all main meals and treatment satisfaction as assessed by the Diabetes Medication Satisfaction (DiabMedSat) questionnaire (0 to 100-point scale with higher scores indicating higher quality of life) [18]. Minor hypoglycaemic episode was defined as an episode with symptoms of hypoglycaemia with the confirmation of blood glucose measurement $<56 \mathrm{mg} / \mathrm{dL}$ ( $3.1 \mathrm{mmol} / \mathrm{l})$ and which was handled by the patient or any asymptomatic blood glucose measurement $<56 \mathrm{mg} / \mathrm{dL}(3.1 \mathrm{mmol} / \mathrm{l})$.

\section{Statistical analyses}

In this predefined subgroup, data were collected at baseline (159 patients), follow-up visit (approximately 13 weeks, 154 patients), and final visit (approximately 26 weeks, 149 patients). The summary of the baseline characteristics and safety data were based on Full Analysis Set (FAS), which consisted of all patients with a baseline visit, had been prescribed BIAsp 30 at least once and did not use BIAsp 30 prior to the start of the study. The analysis of the efficacy outcome variables were based on Efficacy Analysis Set (EAS), which was defined as all patients from FAS who had the final visit, at least one measurement concerning FBG, PPBG, most recent $\mathrm{HbA}_{1 \mathrm{c}}$, weight or hypoglycaemic episodes at baseline and final visit, with the final visit within 18 to 31 weeks from baseline. FBG and PPBG Variability were defined as the standard deviation of the most recent 3 values obtained by the investigator. The analysis of the quality of life (QoL) data was based on Quality of Life Analysis Set (QLAS, 132 patients), which was defined as all patients from FAS who were treated before the study with either OAD or insulin and who had completed at least one item of the DiabMedSat questionnaire at baseline and final visit.

Statistical comparisons of BIAsp 30 outcome measures at baseline and final visit were performed using Wilcoxon signed rank test for discrete variables (hypoglycaemic episodes) and using paired t-test for continuous variables $\left(\mathrm{HbA}_{1 \mathrm{c}}\right.$, mean $\mathrm{FBG}$ and $\mathrm{FBG}$ variability, mean PPBG and PPBG variability). All testing used two-sided tests with significance level $\alpha=0.05$ and were performed using SAS, Version 9.1 (SAS Institute, Cary, NC).

Descriptive statistics were used to summarise hypoglycaemic episodes expressed as both absolute number of episodes and the number of episodes per patient years. The Wilcoxon signed rank test was used to compare the number of hypoglycaemic episodes at baseline and final visit. Descriptive statistics were used to summarise $\mathrm{HbA}{ }_{1 c}$, mean FBG and FBG variability, mean PPBG and PPBG variability. Paired t-test was used to compare $\mathrm{HbA}_{1 \mathrm{c}}$, mean FBG and FBG variability values at baseline and final visit. The test was performed only if values at both visits were present. Discrete variables were displayed in frequency tables. All testing used two-sided tests with significance level $\alpha=0.05$ and were performed using SAS, Version 9.1 (SAS Institute, Cary, NC).

\section{Results}

\section{Baseline demographics}

Of the 478 patients enrolled in Iran, 159 (33.3\%) were previously treated with oral anti-diabetic medications only and 151 of them completed the study. A total of 8 (5.0\%) patients discontinued from the study, due to "lost contact" $(3.1 \%)$ or "other reasons" $(1.9 \%)$. The demographic characteristics of all patients are summarised in Table 1. The patients had mean age of $54.9 \pm 11.1$ years, with a slightly lower rate of males to females (48/52 \%). Mean BMI was $27.1 \pm 4.7 \mathrm{~kg} / \mathrm{m}^{2}$ and mean diabetes duration was $12.6 \pm 7.0$ years. Microvascular complications $(60 \%)$ were more commonly reported than macrovascular complications (34\%) by the patients. The majority of the patients $(73 \%)$ were previously treated with two oral anti-diabetic medications, $9 \%$ patients with more than two oral anti-diabetic medications, and $18 \%$ patients with one oral anti-diabetic medication.

The most common reason for starting a new therapy was to improve FBG (76\%) and for an easy start of insulin therapy (76\%) (Table 2). The mean daily dose of BIAsp 30 after entering into the study (baseline) was $18.3 \mathrm{IU}(0.26 \mathrm{IU} / \mathrm{kg})$ and increased to $48.4 \mathrm{IU}(0.60 \mathrm{IU} / \mathrm{kg})$ at final visit. A majority of patients were injected BIAsp 30 twice daily throughout the study period (56.6\% at baseline and $67.5 \%$ at final visit) (Table 3 ). Patients were exposed to BIAsp 30 for approximately 27.3 weeks.

\section{Safety}

Hypoglycaemic episodes: Major hypoglycaemic episodes

\begin{tabular}{|l|l|}
\hline Total number of patients & 159 \\
\hline Mean age \pm SD (years) & $54.9 \pm 11.1$ \\
\hline Gender, M/F $\%$ ) & $48 / 52$ \\
\hline Mean weight \pm SD $(\mathrm{kg})$ & $73.3 \pm 14.9$ \\
\hline Mean BMI \pm SD $(\mathrm{kg} / \mathrm{m} 2)$ & $27.1 \pm 4.7$ \\
\hline Mean diabetes duration \pm SD (yrs) & $12.6 \pm 7.0$ \\
\hline Mean $\mathrm{HbA}_{1 \mathrm{c}} \pm \mathrm{SD}(\%)$ & $9.3 \pm 2.0$ \\
\hline Macrovascular Complications $(\%)$ & 34 \\
\hline Peripheral vascular disease & 1 \\
\hline Coronary heart disease & 32 \\
\hline Stroke & 2.9 \\
\hline Microvascular Complications (\%) & 60.4 \\
\hline Retinopathy & 29.6 \\
\hline Diabetic nephropathy & 23.3 \\
\hline Peripheral neuropathy & 31.4 \\
\hline Autonomic neuropathy & 5.7 \\
\hline
\end{tabular}

Table 1: Baseline characteristics.

\begin{tabular}{|l|l|}
\hline Reason(s) for starting a new therapy, $\mathrm{n}(\%)$ & Total \\
\hline Easy Start of Insulin Therapy & $121(76.1)$ \\
\hline Easy Intensification of Insulin Therapy & $22(13.8)$ \\
\hline Improve HbA & $106(66.7)$ \\
\hline Improve FBG & $121(76.1)$ \\
\hline Improve PPG & $113(71.1)$ \\
\hline Reduce Risk of Hypoglycaemia & $27(17.0)$ \\
\hline Patient Dissatisfaction with Previous Therapy & $64(40.3)$ \\
\hline Side Effects from Previous Therapy & $12(7.5)$ \\
\hline Change Due To Insulin Pen & $29(18.2)$ \\
\hline Allow For Mealtime Administration & $50(31.4)$ \\
\hline
\end{tabular}

Percentages are based on the number of patients with non-missing values A patient may have findings in more than one category in Reason(s) for starting a new therapy

Table 2: Reason (s) for starting a new therapy.

\begin{tabular}{|l|l|l|}
\hline Injection times & Baseline, $\mathbf{n}(\%)$ & Final visit, $\mathbf{n}(\%)$ \\
\hline 1 time per day & $67(42.1 \%)$ & $7(4.6 \%)$ \\
\hline 2 times per day & $90(56.6 \%)$ & $102(67.5 \%)$ \\
\hline 3 times per day & $2(1.3 \%)$ & $41(27.2 \%)$ \\
\hline 4 times per day & 0 & $1(0.7 \%)$ \\
\hline
\end{tabular}

Table 3: Total number of BIAsp 30 injections. 
Citation: Esteghamati A, Nakhjavani M, Aminorroaya A, Aboutorabi R, M Niafar, et al. (2011) Biphasic Insulin Aspart 30 (BIAsp 30 ) is Safe and Improves Glycaemic Control in Insulin Naïve Patients with Type 2 Diabetes. J Diabetes Metab 2:123. doi:10.4172/2155-6156.1000123

Page 3 of 5

\begin{tabular}{|c|c|c|c|c|}
\hline \multicolumn{2}{|c|}{ Parameter (SD) } & Baseline & Final visit & Absolute change \\
\hline \multicolumn{2}{|c|}{ Mean $\mathrm{HbA}_{1 \mathrm{c}}, \% \mathrm{Hb}$} & $9.26(1.96)$ & $7.49(1.26)$ & $-1.77(1.85)^{\star}$ \\
\hline \multicolumn{2}{|c|}{ Mean FBG, mg/dL } & $222(62)$ & $138(35)$ & $-84(68)^{\star}$ \\
\hline \multirow{3}{*}{$\begin{array}{l}\text { Mean PPBG, } \\
\mathrm{mg} / \mathrm{dL}\end{array}$} & At breakfast & $306(81)$ & $193(52)$ & $-114(86)^{*}$ \\
\hline & At lunch & $226(100)$ & $151(38)$ & $-75(97)$ \\
\hline & At dinner & $266(111)$ & $165(52)$ & $-101(109)$ \\
\hline \multicolumn{2}{|c|}{ Body weight, kg } & $73.70(14.90)$ & $76.39(14.72)$ & $+2.69(5.21)^{\star}$ \\
\hline \multicolumn{2}{|c|}{$\mathrm{BMI}, \mathrm{kg} / \mathrm{m}^{2}$} & $27.24(4.69)$ & $28.30(4.89)$ & $+1.06(1.97)^{\star}$ \\
\hline \multirow{4}{*}{ DiabMedSat } & Overall score & $59.20(12.56)$ & $75.56(11.50)$ & $+16.37(15.78)^{\star}$ \\
\hline & $\begin{array}{l}\text { Relief of } \\
\text { burden }\end{array}$ & $71.26(14.85)$ & $82.90(11.85)$ & $+11.64(17.72)^{*}$ \\
\hline & $\begin{array}{l}\text { Relief of } \\
\text { symptoms }\end{array}$ & $68.10(15.19)$ & $70.43(17.85)$ & $+2.33(20.77)$ \\
\hline & Effectiveness & $38.47(18.51)$ & $73.31(15.98)$ & $+34.84(24.11)^{*}$ \\
\hline
\end{tabular}

FBG: fasting blood glucose

PPG: post prandial glucose

NS: not significan

${ }^{*} p<0.001$

Table 4: Change from baseline in efficacy parameters.
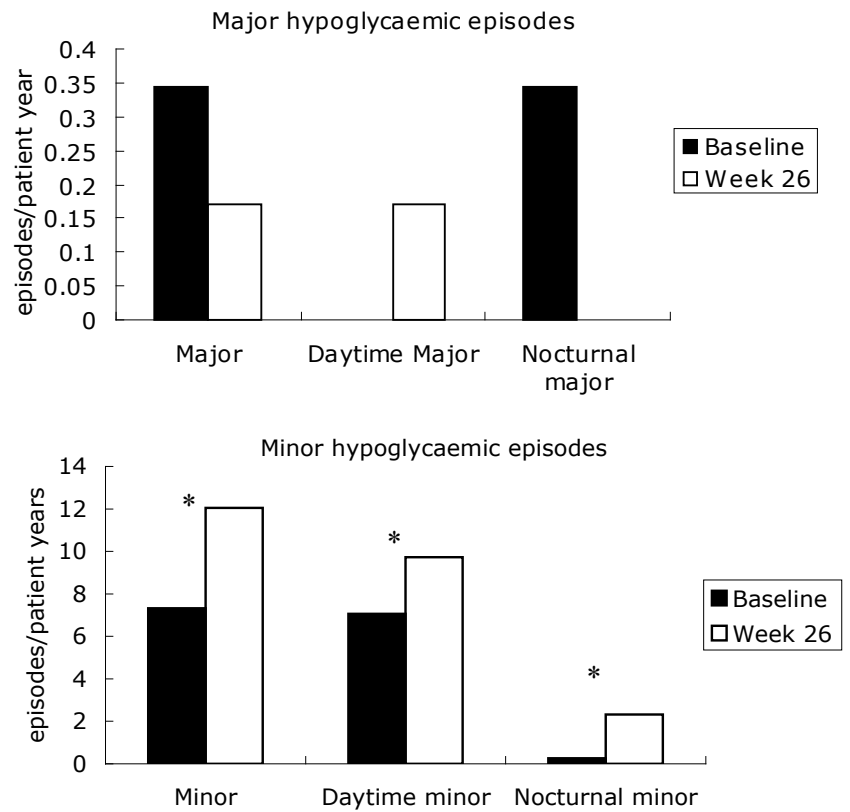

Figure 1: Number of hypoglycaemic episodes (episodes/patient years).

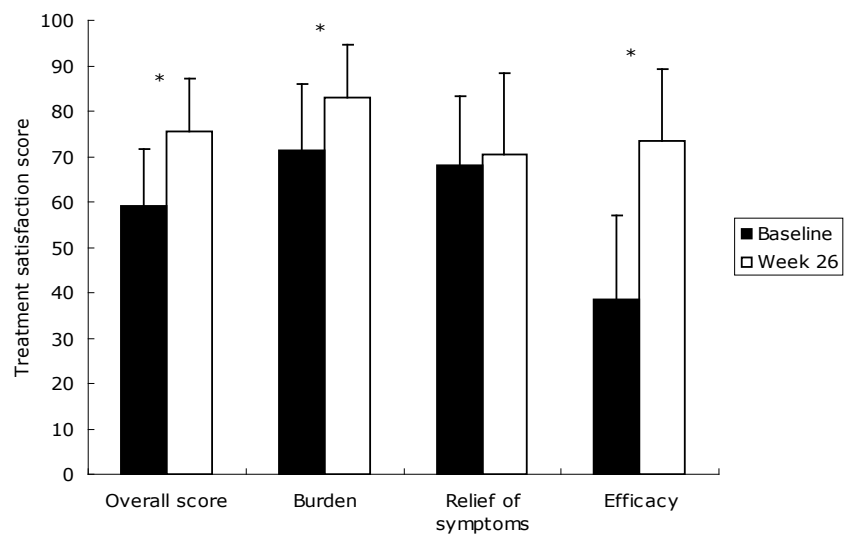

Figure 2: Patient treatment satisfaction among insulin naive patients (DiabMedSat). decreased from 0.344 episodes/patient year at baseline to 0.172 episodes/patient year at final visit, though this decrease was not statistically significant $(\mathrm{p}>0.05)$. From baseline to end of the study, daytime major events were increased by 0.172 episodes per patient year while nocturnal major events were decreased by 0.344 episodes per patient year. Neither of these changes were statistically significant ( $p$ $>0.05)$ Minor hypoglycaemic episodes increased from 7.318 episodes/ patient year at baseline to 12.053 episodes/patient year at final visit $(\mathrm{p}<$ 0.05). Similar trends were observed for daytime minor episodes (7.060 episodes/patient year at baseline to 9.728 episodes/patient year at final visit) as well as nocturnal minor events ( 0.258 episodes/patient years at baseline to 2.325 episodes/patient year at final visit) ( $<0.05$ for both cases; Figure 1).

Adverse events: In the total Iranian cohort ( $\mathrm{N}=478), 22$ adverse events (AEs) were reported and the diagnosis included angina unstable, cardiac arrest, familial tremor, hypoglycaemia, diabetic amyotrophy, haemarthrosis, optic nerve infarction, etc. Among all those reported AEs, 14 events were categorized as serious adverse events (SAEs). A total of 5 AEs (2 SAEs) were categorized as probable, 4 AEs (3 SAEs) were reported as possible and 13 AEs (9 SAEs) were considered as unlikely to be associated with the study medication by study investigators. In Iranian patients, 9 adverse drug reactions (ADRs) were reported and there were 5 serious adverse drug reactions (SADRs) among them. A total of 5 ADRs (2 SADRs) were categorized as probable to be related to the study drug, 4 ADRs (3 SADRs) were possible to be due to the study medication. In Iranian insulin naive subgroup $(\mathrm{N}=159), 8$ AEs were reported in 8 patients and there were 5 reports of SAEs in 5 patients. Four ADRs were reported in 4 patients and there were 3 reports of SADRs in 3 patients in Iranian insulin naive subgroup. In the current study, two major hypoglycaemic episodes were reported by two patients as SADRs.

\section{Body weight}

Compared with baseline, body weight was increased at final visit by $2.69 \pm 5.21 \mathrm{~kg}$. Accordingly, BMI was increased at final visit by $1.06 \pm 1.97$ $\mathrm{kg} / \mathrm{m}^{2}$ (Table 4).

From baseline to final visit, small increases in body weight were observed in different $B M I$ groups $(B M I<25$ group: $4.0 \pm 5.2 \mathrm{~kg}$, $25 \leq \mathrm{BMI}<30$ group: $2.0 \pm 4.4 \mathrm{~kg}, \quad 30 \leq \mathrm{BMI}<35$ group: $2.3 \pm 6.2 \mathrm{~kg}$, in BMI $\geq 35$ group: $2.5 \pm 5.9 \mathrm{~kg}$ )

\section{Effectiveness}

$\mathrm{HbA}_{1 c}$ was $9.26 \pm 1.69 \%$ at baseline and $7.49 \pm 1.26 \%$ at final visit. There was a mean reduction in $\mathrm{HbA}_{1 \mathrm{c}}$ of $1.77 \pm 1.85 \%$ from baseline to final visit.

FBG was reduced from baseline to final visit by $84 \pm 68 \mathrm{mg} / \mathrm{dl}$. Meanwhile, FBG variability was reduced by $16 \pm 17 \mathrm{mg} / \mathrm{dl}$.

Breakfast PPBG was reduced from baseline to final visit by $114 \pm 86$ $\mathrm{mg} / \mathrm{dl}$. Meanwhile, lunch PPBG was reduced by $75 \pm 97 \mathrm{mg} / \mathrm{dl}$ and dinner PPBG was reduced by $101 \pm 109 \mathrm{mg} / \mathrm{dl}$.

\section{Patient treatment satisfaction}

The Diabetes Medication Satisfaction questionnaire evaluated relief of burden, relief of symptoms and effectiveness before and after treatment with BIAsp 30. The overall treatment satisfaction was increased from baseline to final visit (on a 100-point scale, baseline vs. final visit: 59.2 point score vs. 75.6 point score). All three domains showed an improvement in scores from baseline to final visit, while the largest improvement was observed in the efficacy domain (baseline vs. 
Citation: Esteghamati A, Nakhjavani M, Aminorroaya A, Aboutorabi R, M Niafar, et al. (2011) Biphasic Insulin Aspart 30 (BIAsp 30 ) is Safe and Improves Glycaemic Control in Insulin Naïve Patients with Type 2 Diabetes. J Diabetes Metab 2:123. doi:10.4172/2155-6156.1000123

final visit: 38.5 point score vs.73.3 point score). A small increase was also observed in the relief of burden (baseline vs. final visit: 71.3 point score vs.82.9 point score) (Figure 2).

\section{Discussion}

IMPROVE ${ }^{\mathrm{TM}}$ is a 26-week, open-label, non-randomized, multicentre observational study to evaluate the safety and efficacy of BIAsp 30 in type 2 diabetic patients under the routine clinical practice. The results from the Iranian cohort of insulin naïve patients with type 2 diabetes show that insulin initiation with BIAsp 30 is a safe and effective method of insulin therapy. Glycaemic control and treatment satisfaction was improved without an increased risk of major hypoglycaemic episodes. These results in the Iranian cohort are in concordance with the findings of the global IMPROVE ${ }^{\text {tix }}$ study [19-22].

After 26 weeks of treatment with BIAsp 30, there was no increase in risk of major hypoglycaemic episodes in insulin naïve Iranian patients with type 2 diabetes and this is consistent with the global IMPROVE ${ }^{\text {tw }}$ study [20]. However, there was an increased risk of minor hypoglycaemic episodes in insulin naïve Iranian patients with type 2 diabetes, which was also consistent with both the Iranian and global cohort of insulin naïve patients [20].

Body weight in Iranian patients previously treated with OADs only was increased by $2.7 \mathrm{~kg}$ after 26 weeks of treatment, which was slightly higher than the increase of $1.7 \mathrm{~kg}$ in the overall Iranian cohort [23]. It is consistent with the UKPDS data where insulin treatment is associated with a weight gain [3]. Furthermore, small increases in body weight were observed in all different BMI groups in this study.

In this study, BIAsp 30 improved the glycaemic control in insulin naive Iranian patients with type 2 diabetes. Mean $\mathrm{HbA}_{1 c}$ was significantly reduced after 26 weeks of treatment. This result is consistent with that of the overall Iranian cohort and the global cohort [20]. These patients had long diabetes duration, poor glycaemic control, and most were treated with two or more OADs. Furthermore, $60 \%$ of patients reported microvascular complications, while $34 \%$ of recruited patients reported macrovascular complications in their past medical history. All these findings imply that insulin treatment should have been initiated earlier. The incidence of clinical complications is significantly associated with glycaemic level. In UKPDS study it has been shown that each $1 \%$ reduction in mean $\mathrm{HbAlc}$ was associated with reduction of $14 \%$ in incidence of myocardial infarction, $21 \%$ for deaths related to diabetes, $37 \%$ for microvascular complications and $43 \%$ in peripheral vascular disease [24].

In this trial, the clear benefits with BIAsp 30 regimen were the larger reductions in FBG, FBG variability and PPBG. Therefore, BIAsp 30 not only provides basal insulin coverage but also effectively controls the postprandial component of glycaemic parameters, consistent with the finding in other clinical trials [25].

The overall treatment satisfaction was improved after treatment with BIAsp 30, which is consistent with the finding in the overall Iranian cohort and the global study [20]. The largest improvement was observed in the efficacy domain and this is not unexpected since the most cited reason for starting a new therapy was to improve glycaemic control An improvement in treatment satisfaction may enhance treatment and self-management. A small increase was also observed in the relief of burden. It should be emphasized that BIAsp 30 treatment led to beneficial effect on relief burden of the treatment despite the start of a difficult therapy such as insulin. The patients who were previously insulin naïve started insulin injection once daily or majority twice daily. However, they had increased relief of burden after BIAsp 30 treatment.
The improved glycaemic control in the present observational study is consistent with the fact that most physicians decide to initiate treatment with BIAsp 30 in order to improve FBG and for an easy start of insulin therapy. A study effect could also contribute partially to this improvement. Heterogeneity of real-life populations and the absence of a control group in observational studies may limit the conclusions we can draw from them.

There are also limitations with the current study. The lack of randomization and the lack of other treatment arms added confounding factors to the study. In addition, other parameters regarding lipids metabolism and insulin resistance may be informative; however, we did not investigate into detail.

In summary, initiating BIAsp 30 in insulin naïve Iranian patients with type 2 diabetes was safe and effective. Treatment with BIAsp 30 improved glycaemic control and patient treatment satisfaction without an increased risk of major hypoglycaemia. Furthermore, the results in Iranian patients are consistent with the global IMPROVE ${ }^{\text {min }}$ study cohort.

\section{Acknowledgements}

Special thanks are given to all the patients and investigators for their participation in this study. The IMPROVE ${ }^{\mathrm{TM}}$ study was sponsored by Novo Nordisk A S, Denmark. Medical writing support was provided by Yang N, Novo Nordisk International Operations Clinical Development Center, Statistical support was provided by $\mathrm{Hu} \mathrm{H}$, Novo Nordisk International Operations Clinical Development Centre.

\section{References}

1. American Diabetes Association (2007) Diagnosis and classification of diabetes mellitus. Diabetes Care 1: S42-47.

2. Nathan DM, Buse JB, Davidson MB, Davidson MB, Ferrannini E, et al. (2009) Medical management of hyperglycemia in type 2 diabetes: a consensus algorithm for the initiation and adjustment of therapy: a consensus statement of the American Diabetes Association and the European Association for the Study of Diabetes. Diabetes Care 32:193-203.

3. Turner RC, Holman RR, Cull CA (1998) Intensive blood-glucose control with sulphonylureas or insulin compared with conventional treatment and risk of complications in patients with type 2 diabetes (UKPDS 33). UK Prospective Diabetes Study (UKPDS) Group. Lancet 352:837-853.

4. Hanefeld M, Fischer S, Julius U, Schulze J, Schwanebeck U, et al. (1996) Risk factors for myocardial infarction and death in newly detected NIDDM: the Diabetes Intervention Study, 11-year follow-up. Diabetologia 39:1577-1583.

5. Monnier L, Lapinski H, Colette C (2003) Contributions of fasting and postprandial plasma glucose increments to the overall diurnal hyperglycemia of type 2 diabetic patients - Variations with increasing levels of $\mathrm{HbA}(1 \mathrm{c})$. Diabetes Care 26:881-885.

6. Monnier L, Colette C (2008) Targeting prandial hyperglycemia: how important is it and how best to do this? Curr Diab Rep 8: 368-374.

7. Rolla AR, Rakel RE (2005) Practical approaches to insulin therapy for type 2 diabetes mellitus with premixed insulin analogues. Clin Ther 27: 1113-1125.

8. Kvapil A, Swatko A, Hilberg C, Shestakova A (2006) Biphasic insulin aspart 30 plus metformin: an effective combination in type 2 diabetes. Diabetes Obes Metab 8: 39-48.

9. Luzio S, Dunseath G, Peter R, Pauvaday V, Owens DR (2006) Comparison of the pharmacokinetics and pharmacodynamics of biphasic insulin aspart and insulin glargine in people with type 2 diabetes. Diabetologia 49:1163-1168.

10. Garber AJ, Wahlen J, Wahl T, Bressler P, Braceras R, et al. (2006) Attainment of glycaemic goals in type 2 diabetes with once-, twice-, or thrice-daily dosing with biphasic insulin aspart 70/30 (The 1-2-3 study). Diabetes Obes Metab 8: 58-66.

11. McSorley PT, Bell PM, Jacobsen LV, Kristensen A, Lindholm A (2002) Twicedaily biphasic insulin aspart 30 versus biphasic human insulin 30: a doubleblind crossover study in adults with type 2 diabetes mellitus. Clin Ther 24: 530 539.

12. Ligthelm RJ, Mouritzen U, Lynggaard H, Landin-Olsson M, Fox C, et al. (2006) 
Citation: Esteghamati A, Nakhjavani M, Aminorroaya A, Aboutorabi R, M Niafar, et al. (2011) Biphasic Insulin Aspart 30 (BIAsp 30) is Safe and Improves Glycaemic Control in Insulin Naïve Patients with Type 2 Diabetes. J Diabetes Metab 2:123. doi:10.4172/2155-6156.1000123

Page 5 of 5

Biphasic insulin aspart given thrice-daily is as efficacious as a conventional basal bolus insulin regimen with four daily injections in subjects with type 2 diabetes. Exp Clin Endocrinol Diabetes 114: 511-519.

13. Delavari A, Alikhani S, Nili S, Birjandi RH, Birjandi F (2009) Quality of care of diabetes mellitus type II patients in Iran. Arch Iran Med 12:492-495.

14. Valensi P, Benroubi M, Borzi V, Gumprecht J, Kawamori R, et al. (2008) The IMPROVE study--a multinational, observational study in type 2 diabetes: baseline characteristics from eight national cohorts. Int J Clin Pract 62: 18091819.

15. Gumprecht J, Benroubi M, Borzi V, et al. (2009) Intensification to biphasic insulin aspart 30/70 (BIAsp 30, NovoMix 30) can improve glycaemic control in patients treated with basal insulins: a subgroup analysis of the IMPROVE observational study. Int J Clin Pract 63: 966-972.

16. World Medical Association Declaration of Helsinki: ethical principles for medica research involving human subjects. JAMA 2000; 284: 3043-3045.

17. International Conference on Harmonisation of Technical Requirements for Registration of Pharmaceuticals for Human Use $(\mathrm{ICH})$ adopts Consolidated Guideline on Good Clinical Practice in the Conduct of Clinical Trials on Medicinal Products for Human Use. Int Dig Health Legis 1997; 48: 231-234.

18. Brod M, Skovlund SE, Wittrup-Jensen KU (2006) Measuring the impact of diabetes through patient report of treatment satisfaction, productivity and symptom experience. Qual Life Res 15: 481-491.

19. Gumprecht J, Benroubi M, Borzi V, Kawamori R, Shaban J, et al. (2009) Intensification to biphasic insulin aspart 30/70 (BIAsp 30, NovoMix ((R)) 30) can improve glycaemic control in patients treated with basal insulins: a subgroup analysis of the IMPROVE (TM) observational study. Int J Clin Pract 63: 966972

20. Valensi P, Benroubi M, Borzi V, Gumprecht J, Kawamori R, et al. (2009) Initiating insulin therapy with, or switching existing insulin therapy to, biphasic insulin aspart 30/70 (NovoMix 30) in routine care: safety and effectiveness in patients with type 2 diabetes in the IMPROVE observational study. Int $\mathrm{J}$ Clin Pract 63: 522-531.

21. Valensi P, Benroubi M, Borzi V, Gumprecht J, Kawamori R, et al. (2008) The IMPROVE (TM) study - a multinational, observational study in type 2 diabetes: baseline characteristics from eight national cohorts. Int J Clin Pract 62: 1809-1819.

22. Yang WY, Ji QH, Zhu DL, Chen L, Liu Z, et al. (2008) Biphasic insulin aspart 30 three times daily is more effective than a twice-daily regimen, without increasing hypoglycemia, in Chinese subjects with type 2 diabetes inadequately controlled on oral antidiabetes drugs. Diabetes Care 31: 852-826.

23. Esteghamatia A, Rajabianb R, Amini M, Bahrami A, Khamseh ME, et al. (2010) Safety and efficacy of biphasic insulin aspart 30 (BIAsp 30) in Iranians with type 2 diabetes: an open-label, non-randomised, multi-centre observational study. Endokrynol Pol 61: 364-370.

24. Stratton IM, Adler AI, Neil HA, Matthews DR, Manley SE, et al. (2000) Association of glycaemia with macrovascular and microvascular complications of type 2 diabetes (UKPDS 35): prospective observational study. BMJ 321: 405412.

25. Christiansen JS, Vaz JA, Metelko Z, Bogoev M, Dedov I (2003)Twice daily biphasic insulin aspart improves postprandial glycaemic control more effectively than twice daily NPH insulin, with low risk of hypoglycaemia, in patients with type 2 diabetes. Diabetes Obes Metab 5: 446-454. 